\title{
NOTÍCIES
}

\section{Nova coordinació de les Jornades d'Estudis Locals de les Illes Balears}

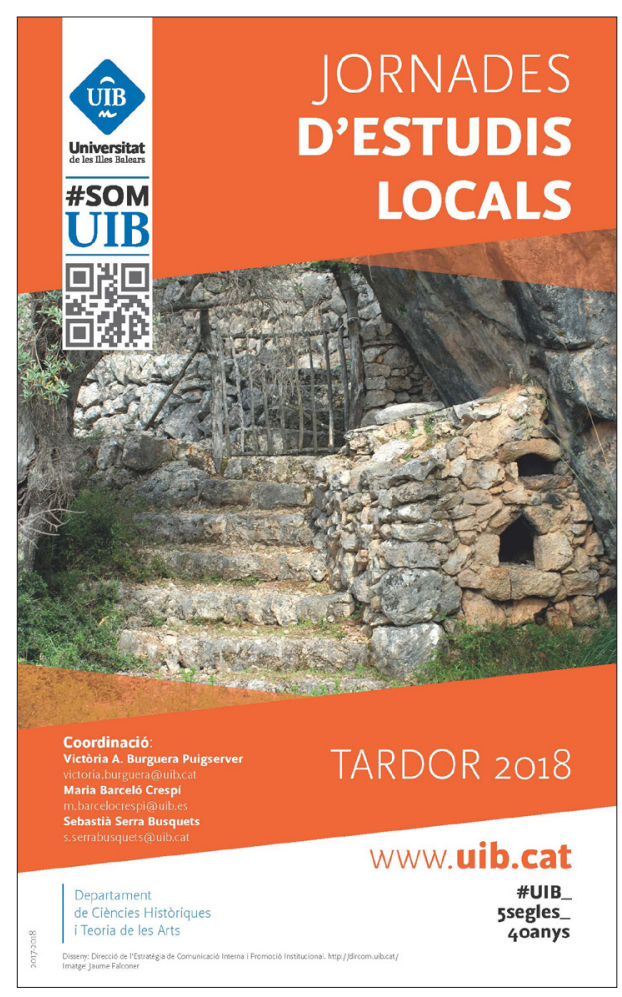

pulsor de la recerca a les Illes. Una recerca que abraça diversos àmbits del saber, des de les humanitats a les ciències naturals, des del patrimoni als estudis mediambientals, en un marc cronològic ampli i amb un únic comú denominador: l'espai en el qual tenen lloc, l'àmbit local. Tot al contrari de considerar aquests estudis tancats i esgotats en la seva reduïda circumscripció geogràfica, constitueixen una aportació i una contribució valuosa al coneixement del conjunt del territori de les Illes Balears. Les anàlisis d'àmbit local no deixen de ser recerques sobre Mallorca, Menorca, Eivissa i Formentera i, per tant, un tribut al coneixement dels fenòmens que s'esdevenen en un espai concret, però amb cabuda en medis més amplis.

Per tal que l'adjectiu «local» que les defineix, més enllà de referenciar una limitació geogràfica, no es converteixi en determinant d'una suposada escassesa de rigor científic i d'un caràcter anecdòtic i erudit, d'acord amb la connotació negativa de vegades atribuïda a aquests estudis, és d'una importància cabdal que les jornades es dotin d'un comitè científic rigorós i plural, que sigui garant de la qualitat de les aportacions. D'aquí l'especial interès del Departament a contribuir especialment a potenciar aquest aspecte, característic d'un compromís compartit per la Universitat i els organitzadors de les diverses jornades.

Per altra banda, és destacable l'atractiu i la rebuda social que tenen aquests estudis dins l'àmbit local. Es conformen com a espai dialèctic entre la comunitat científica i el conjunt de la societat, i exerceixen de pont entre el saber i la comunitat. Per als investigadors locals, també representen una oportunitat per fer públiques les recerques i contribuir tant al coneixement científic com al popular. La forta empenta 
experimentada per aquests estudis els darrers anys es podria interpretar, igualment, com una creixent curiositat i un major interès per part de la societat envers el lloc d'origen o residència, que tant els ajuntaments com les diverses associacions o organitzacions han sabut canalitzar.

Entre les temàtiques més recurrents en aquests tipus d'estudis, les relacionades amb la història i l'art, fortament lligades al patrimoni cultural, han gaudit sempre d'un paper principal. No és d'estranyar, doncs, la voluntat del Departament de Ciències Històriques i Teoria de les Arts d'implicar-se en la celebració d'aquestes iniciatives. Aquesta implicació s'ha plantejat en una doble direcció: per una banda, a través de la col-laboració amb els organitzadors, a fi de garantir una certa qualitat científica de les aportacions i, per altra banda, per mitjà de la coordinació entre els diferents promotors, per tal d'assegurar-hi una equitativa participació $i$ assistència $\mathrm{i}$ vetllar perquè unes jornades i altres no es vegin perjudicades en matèria de dates o objectes d'estudi.

Des de 2017, moment en què s'inicià el projecte, som tres les persones del Departament encarregades d'aquest propòsit: el doctor Sebastià Serra Busquets, director del Departament de Ciències Històriques i Teoria de les Arts; la doctora Maria Barceló Crespí, catedràtica d'Història Medieval; i jo mateixa, Victòria A. Burguera i Puigserver, becària predoctoral del mateix Departament de la UIB. La nostra primera iniciativa va ser notificar als batlles i batllesses dels cinquanta-tres municipis de Mallorca les intencions del Departament de posar-se al capdavant de la coordinació de les jornades d'estudis locals i, a la vegada, oferir una sèrie d'ajuts als ajuntaments o associacions organitzadores que hi estiguessin interessats, sobretot en referència a la conformació dels comitès científics i a la difusió dels esdeveniments. La mateixa notificació i oferiment s'envià també a l'Institut d'Estudis Eivissencs, a l'Ateneu de Maó, al Centre d'Estudis Locals d'Alaior i a la Societat Historicoarqueològica Martí i Bella de Ciutadella, centres encarregats de promocionar els estudis de caràcter local a Eivissa i a Menorca, respectivament.

Així doncs, en termes de col-laboració, des d'aleshores el Departament manté el personal docent i investigador a disposició de les entitats organitzadores d'aquestes iniciatives, perquè puguin figurar com a membres dels comitès científics o com a ponents de les lliçons inaugurals. Igualment, s'ofereix la possibilitat d'emetre certificats d'assistència i de participació conjunts, signats per la institució organitzadora de les jornades i pel Departament de la Universitat, la qual cosa pretén ser també un reclam a la seva concurrència.

D'altra banda, com a mitjà de coordinació de les diverses iniciatives, el Departament elaborarà anualment un calendari amb les dates i la informació de totes les que es duran a terme durant aquell any. Així, a part d'evitar que les jornades es vegin superposades les unes amb les altres i de garantir-hi la màxima assistència i participació, se'n podrà fer fâcilment difusió entre el professorat i l'alumnat de la UIB. La intenció és que aquest calendari sigui accessible no només a través de la Universitat, sinó també en arxius, biblioteques o altres zones on concorren tant l'alumnat com el personal investigador. En aquesta línia, també s'ha previst la dotació d'un espai al Departament perquè funcioni com a dipòsit de totes les publicacions que sorgeixin com a fruit d'aquestes iniciatives.

En resum, l'objectiu d'una creixent intervenció del Departament i d'un augment de la presència del seu personal en els diversos estudis que es duen a terme a i sobre les Illes és triple: contribuir a la qualitat del coneixement que es crea any rere any en l'àmbit local; difondre les recerques en curs sobre el territori illenc i donar-hi visibilitat; i, en darrer lloc, promocionar un accés ordenat, fâcil i proper al saber, sigui en l'àmbit que sigui, per tal que es pugui convertir en estímul per a futures investigacions.

Després d'algun temps de la posada en marxa d'aquest projecte, en podem fer ja les primeres valoracions. La nostra proposta va tenir una gran acollida a les jornades de 2017, i aquesta acollida ha anat en augment el 2018. El primer calendari inclogué solament les celebrades durant els mesos de la tardor de 2017, que foren la gran majoria, i les que, d'una manera o l'altra, es varen posar en contacte amb el Departament. Aquestes foren: les VI Jornades de Búger, les I Jornades de Ses Salines, les III Jornades de Calvià, les I Jornades de Sencelles, les I Jornades de Llucmajor, les II Jornades de Lloret de Vistalegre i 
les XVIII Jornades d'Inca. Igualment, durant el mes de novembre se celebraren les II Jornades de Cultura Popular i Tradicional de les Illes Balears i les XXV Jornades d'Estudis Històrics Locals de l'Institut d'Estudis Baleàrics, aquesta vegada dedicades als estudis de cinema i audiovisual. Aquestes dues darreres iniciatives, celebrades a Eivissa, també foren incloses en el calendari. De totes maneres, encara que aquest primer només comprengué una part dels esdeveniments, el nostre propòsit és que, a mesura que la collaboració del Departament es normalitzi en la majoria de les jornades d'estudi, el calendari dels propers anys pugui ser anual i incloure-hi, si no la totalitat, sí la major part d'aquests projectes.

El Departament estigué representat activament en els comitès científics de les primeres jornades de Ses Salines, de les segones jornades de Lloret, de les terceres jornades de Calvià i de les primeres de Llucmajor. A més, tant a les de Calvià com a les de Ses Salines fou també un professor del Departament de Ciències Històriques i Teoria de les Arts l'encarregat de dur a terme la lliçó inaugural, a petició dels organitzadors. A les III Jornades de Calvià, aquesta tasca fou encomanada al doctor Manuel Calvo Trias, professor de Prehistòria, que presentà la lliçó titulada «Paisatge i comunitat durant la prehistòria. El cas de Calvià». A Ses Salines, en canvi, l'encarregat d'inaugurar les primeres jornades del municipi fou el professor Enrique García Riaza, catedràtic d'Història Antiga, amb la dissertació «La presència romana en el sud de Mallorca».

Les jornades del curs 2018-19 s'han tornat a presentar amb igual o més força que les anteriors i la gran majoria concentrades en els mesos d'octubre i novembre. La col-laboració del Departament ha estat confirmada a les I Jornades de Mancor de la Vall, a les III Jornades de Montuïri, a les II Jornades de Campos, a les II Jornades de Llucmajor, a les XIII Jornades de Sóller i Fornalutx, a les V Jornades de Marratxí i a les I Jornades de Costitx.

Des del Departament de Ciències Històriques i Teoria de les Arts de la Universitat de les Illes Balears continuarem esforçant-nos per preservar, difondre i donar qualitat al coneixement sobre la història, l'art, la cultura, el patrimoni i el saber de les Illes. No podem fer més que desitjar que la flama que fins ara ha impulsat i guiat els estudis locals duri i es mantengui viva per molts anys més.

Victòria A. Burguera Puigserver Universitat de les Illes Balears 